\title{
PLANO DE REFORMULAÇÃO DA ASSISTENCIA AMBULATORIAL DO INSTITUTO NACIONAL DE PREVIDENCIA SOCIAL NA CIDADE DE SÃO PAULO
}

\author{
Ernesto LIMA-GONÇALVES * \\ Milton FUCHS ** \\ Arthur de ALMEIDA *** \\ Taka OGUISSO **
}

\section{RSPSP-125}

Lima-Gonçalves, E. et al. - Plano de re formulação da assistência ambulatorial do Instituto Nacional de Previdência Social na cidade de São Paulo. Rev. Saúde públ., São Paulo, 6:135-46, 1972 .

Resumo: Foi apresentado plano de reformulação da assistência ambulatorial prestada pelo Instituto Nacional de Previdência Social a seus segurados e respectivos dependentes, na cidade de São Paulo, salientando, que uma avaliação desse tipo assume importância considerável, diante da carência de leitos hospitalares disponíveis. A primeira etapa do plano consistiu no levantamento da situação atual, o qual compreendeu três aspectos: quantitativos de pessoal, dimensionamento das instalações, localização em relação à area urbana. O resultado demonstrou deficiências em todos os Postos de Assistência, sob os três pontos de vista analisados. Foi elaborado plano de reformulação da rede ambulatorial, tomando por base a população previdenciária da cidade de São Paulo, a qual é de cerca de 4.500 .000 pessoas. Esse plano funda-se em quatro premissas fundamentais: 1 . dimensionamento adequado de unidades a serem construídas e definição das que deverão ser mantidas, de acordo com as necessidades das diferentes zonas da cidade; 2. localização adequada das novas unidades; 3. implantaçâo de sistemas de unidades periféricas resultantes da integração de unidades da Secretaria da Saúde do Estado de São Paulo; 4. definiçấo de retaguarda hospitalar adequada. O total de atendimentos capazes de serem oferecidos pela rede de Postos de Assistência, assim constituída, é de cerca de 5.000.000 por ano.

UNITERMos: Ambulatórios, assistência"; Previdência social*; São Paulo, Brasil*; Assistência comunitária.

\section{N T ROD U C AO}

A Organização Mundial da Saúde ${ }^{4}$, define o ambulatório como "um centro encarregado de fomentar a saúde e prevenir as enfermidades, servindo de vinculo entre o Hospital, os serviços sanitários locais e a comunidade".

Essa conceituação insere o ambulatório como elemento de alto valor no conjunto de equipamentos médico-assistenciais à disposição de uma comunidade. fácil perceber que um conjunto de ambulatorios, bem planejado individualmente $e$ harmoniosamente inserido num plano global de assistência, poderá aliviar de modo substancial a sobrecarga que pesa habitualmente sobre os hospitais ${ }^{1}$.

\footnotetext{
* Da Faculdade de Medicina da USP. - Av. Dr. Arnaldo, 455 - Săo Paulo, SP., Brasil. Assistência Médica do INPS para o Estado de Săo Paulo.

** Do Grupo de Planejamento de Superintendência Regional do INPS em São Paulo.

*** Da Coordenação de Assistência Médica do INPS em São Paulo.
} 
LIMA-GONCGALVES, E. et. al. - Plano de reformulaçăo da assistencia ambulatorlal do Instituto Nacional de Previdência Social na cidade de São Paulo. Rev. Saúde públ., S. Paulo, 6: 135-46, 1972.

O fato assume importância relevante, quando já existe carência mais ou menos considerável de leitos hospitalares. Em outro trabalho 2 , procuramos analisar a situação que vivemos no Estado de São Paulo no momento, em termos de assistência hospitalar; caracterizamos alí uma carência tão grande de leitos à disposição da comunidade, para internações hospitalares, que chega a constituir-se, na nossa opinião, em grave problema de saúde pública.

A análise referida foi feita tendo em vista a população sob responsabilidade da Previdência Social no Estado de São Paulo; os números, contudo, podem tranquilamente ser transpostos para a população em geral.

Dentro desse contexto, o exame da situação em que se encontra a assistência médica ambulatorial do Instituto Nacional de Previdência Social (INPS), em São Paulo, representa passo de extremo valor para a avaliação dos níveis globais de assistência médica. A correção das eventuais distorçôes e das carências verificadas representará, com certeza, a possibilidade de aliviar a carência de atendimento hospitalar, decorrente da deficiência de leitos, além de melhorar o padrão do atendimento ambulatorial, válido em si mesmo, como forma de assistência à comunidade.

Em face dessas colocações, o Grupo de Planejamento da Superintendencia Regional do INPS, em São Paulo, realizou uma análise da situação atual dos ambulatórios do Instituto na cidade de São Paulo, como passo inicial para uma reformulação desse atendimento.
SITUAÇAO DOS AMBULATORIOS DO INPS NA CIDADE DE SaO PaULo

O INPS conta, na capital do Estado, com diferentes tipos de postos de assistência ambulatorial. $O$ mais simples deles denomina-se Serviço de Pronto Atendimento (SPA), em número de 3 ; trata-se de unidade capacitada apenas para consultas de clínica geral, não contando com serviços especializados e funcionando de 7.00 às 19.00 horas. O segundo tipo, com um único posto, é chamado Posto de Urgência (PU), funcionando continuamente durante 24 horas, sem incluir também consultas em clínicas especializadas. O terceiro tipo é o Posto de Atendimento (PA), que funciona no período de $\mathbf{7 . 0 0}$ às 19,00 horas e contando com recursos assistenciais proporcionais a seu porte físico; em outros termos, encontramos aqui desde PAs que dispõem apenas do atendimento de clínica médica geral e que poderemos chamar de tipo $B$ (em número de 7), até aqueles onde funcionam serviços ambulatoriais das mais diversas especialidades; estes correspondem aos de tipo $A$, em número de 8 .

A análise da situação realizada revelou deficiências de diversas naturezas, em especial: 1 - carência de pessoal; 2 deficiência de instalaçóes; 3 - inadequação de localização.

As tabelas 1 e 2 caracterizam a situação de deficiências do pessoal nas diversas categorias de ambulatórios à disposição dos previdenciários na cidade de São Paulo. Em ambos, o pessoal previsto foi estimado em relação ao ritmo atual de atendimento do PA. 
LIMA-GONCALVES, E. et. al. - Plano de reformulaçăo da assisténcia ambulatorial do Instituto Nacional de Previdência Social na cidade de São Paulo. Rev. Saúde públ., S. Paulo, 6: 135-46, 1972.

T A B E L A 1

"Deficit" de servidores nos ambulat6rios tipos SPA e PU do INPS na cldade de Sáo Paulo - 1972

\begin{tabular}{|c|c|c|c|c|c|c|c|c|c|c|c|}
\hline \multirow{3}{*}{$\begin{array}{c}\text { Tipo } \\
\text { de } \\
\text { ambu- } \\
\text { latório }\end{array}$} & \multirow{3}{*}{$\begin{array}{l}\text { Identificação } \\
\text { do } \\
\text { ambulatório }\end{array}$} & \multicolumn{9}{|c|}{ Categoria dos servidores } & \multirow{3}{*}{$\begin{array}{c}\text { "Deficit" } \\
\text { total }\end{array}$} \\
\hline & & \multicolumn{3}{|c|}{ Administrativos } & \multicolumn{3}{|c|}{ Médicos } & \multicolumn{3}{|c|}{ Enfermagem } & \\
\hline & & (1) & (2) & (3) & (1) & (2) & (3) & (1) & (2) & (3) & \\
\hline \multirow{3}{*}{ SPA } & Agua Rasa & 8 & 4 & 4 & 15 & 16 & -1 & 5 & $\mathbf{5}$ & 0 & 3 \\
\hline & Freg. do 6 & 9 & 6 & 3 & 20 & 17 & 3 & 5 & 5 & 0 & 6 \\
\hline & Vila Maria & 8 & 5 & 3 & 15 & 10 & 5 & 5 & 4 & 1 & 9 \\
\hline PU & Sta. Cecília & 12 & 11 & 1 & 38 & 36 & 2 & 15 & 14 & 1 & 4 \\
\hline
\end{tabular}

(1) Número de funcionários previstos

(2) Número de funcionários existentes

(3) "Deficit" de funcionários por categoria.

TA B E L A 2

"Deficit" de servidores nos ambulatórios (PAS) tipo A e B do INPS na cidade de São Pauio - 1972.

\begin{tabular}{|c|c|c|c|c|c|c|c|c|c|c|c|}
\hline \multirow{3}{*}{$\begin{array}{l}\text { Tipo } \\
\text { de } \\
\text { PA }\end{array}$} & \multirow{3}{*}{$\begin{array}{c}\text { Identificação } \\
\text { do } \\
\text { ambulatório }\end{array}$} & \multicolumn{9}{|c|}{ Categoria dos servidores } & \multirow{3}{*}{$\begin{array}{c}\text { "Deficit" } \\
\text { total }\end{array}$} \\
\hline & & \multicolumn{3}{|c|}{ Administrativos } & \multicolumn{3}{|c|}{ Médicos } & \multicolumn{3}{|c|}{ Enfermagem } & \\
\hline & & (1) & (2) & '(3) & (1) & (2) & (3) & (1) & (2) & (3) & \\
\hline \multirow{8}{*}{ A } & $\begin{array}{l}\text { Conselheiro } \\
\text { Crispiniano }\end{array}$ & 45 & 32 & 9 & 240 & 148 & 92 & 60 & 43 & 7 & 118 \\
\hline & V. do Carmo & 33 & 33 & - & 106 & 96 & 10 & 50 & 45 & 5 & 15 \\
\hline & S. Antonio & 45 & 30 & 15 & 147 & 140 & 7 & 50 & 45 & 5 & 27 \\
\hline & $\begin{array}{c}\text { Martins } \\
\text { Fontes }\end{array}$ & 70 & 42 & 28 & 230 & 205 & 25 & 52 & 52 & - & 63 \\
\hline & Catão & 30 & 26 & 4 & 95 & 100 & -5 & 40 & 29 & 11 & 10 \\
\hline & Tatuajé & 30 & 24 & 6 & 110 & 91 & 19 & 40 & 35 & 5 & 30 \\
\hline & Brigadeiro & 26 & 26 & - & 130 & 124 & 6 & 52 & 33 & 19 & 25 \\
\hline & Cleveland & 14 & 8 & 6 & 47 & 48 & -1 & 21 & 14 & 7 & 12 \\
\hline \multirow{7}{*}{ B } & Sta. Cruz & 7 & 6 & 1 & 23 & 21 & 2 & 10 & 10 & - & 3 \\
\hline & Sto. Amaro & 12 & 11 & 1 & 37 & 31 & 6 & 21 & 17 & 4 & 11 \\
\hline & Cidade Dutra & 4 & 2 & 2 & 10 & 9 & 1 & 3 & 3 & - & 3 \\
\hline & 9 de Julho & 2 & 1 & 1 & 8 & 9 & -1 & 3 & 3 & - & 0 \\
\hline & Brás & 6 & 4 & 2 & 17 & 21 & -4 & 6 & 4 & 2 & 0 \\
\hline & Agua Branca & 12 & 11 & 1 & 37 & 47 & -10 & 21 & 14 & 7 & -2 \\
\hline & Aeroporto & 4 & 3 & 1 & 7 & 6 & 1 & 6 & $\mathbf{3}$ & 3 & 5 \\
\hline
\end{tabular}

(1) Número de funcionários previstos

(2) Número de funcionários existentes

(3) "Deficit" de funcionários por categoria. 
LIMA-GONÇALVES, E. et. al. - Plano de reformulação da assistencia ambulatorial do Instituto Nacional de Previdencia Social na cidade de São Paulo. Rev. Saúde públ., S. Paulo, 6: 135-46, 1972.

Observa-se, nas Tabelas 1 e 2, a extrema disparidade entre os números previstos e os existentes, nas categorias de pessoal administrativo e de enfermagem em todos os tipos de unidades ambulatoriais (PU, SPA, PA tipo A e PA tipo B) e em cada uma dessas unidades. Não se observa carência semelhante no que se refere a médicos, donde poder-se concluir que uma das causas fundamentais da deficiência de atendimento ambulatorial aos segurados da Previdência Social, na cidade de São Paulo, é exatamente a ca. rência de pessoal para-médico. O fato, aliás, repete-se nas demais áreas da Superintendência Regional do INPS em São Paulo: pelo menos neste Estado, existem funcionários em número muito inferior ao que seria indispensável para a execução adequada das tarefas assumidas pela Previdência Social.

A segunda tentativa de caracterização dos ambulatórios refere-se a suas instalações, do ponto de vista de seu dimensionamento. Embora as estatísticas internacionais assinalem números muito superiores, achamos razoável para o nosso meio a definição da área total do ambulatório em torno de $10 \mathrm{~m}^{2}$ para cada usuário, em determinado turno de atendimento. Em outra publicação 3 procuramos definir as proporçóes segundo as quais a área total calculada dessa maneira pode ser distribuída pelos diferentes setores do ambulatório. No trabalho referido, esses diversos setores distribuem-se da seguinte maneira: 1 - área de atendimento, incluindo área de espera, área de serviços médicos e área de enfermagem; a estas áreas correspondem aproximadamente $49 \%$ da área total do ambulatório, cabendo a cada um dos setores indicados respectivamente $8,5 \%$, $25,5 \%$ e $15 \% ; 2$ - área de serviços auxiliares compreendendo cêrca de $16 \%$ da área total; 3 - área de administração, correspondendo a 5\%; 4 - área de serviços gerais, que abrange cêrca de $30 \%$ do total do ambulatório. Com base no dado referido para o cálculo da área global do ambulatório, bem como nas proporções referidas, procurámos dimensionar o que seria de se prever para cada ambulatório existente, em função da demanda de seus serviços, para poder comparar com o que existe na realidade. o que mostram as tabelas 3 e 4 , onde os valores são expressos $\mathrm{em} \mathbf{m}^{2}$.

A análise das Tabelas 3 e 4 revela que, em termos gerais, existe uma desproporção entre o número de atendimentos que cada uma das unidades presta e suas dimensões físicas. Na verdade, apenas em dois casos - SPA-Agua Rasa e PA-Cidade Dutra - as áreas mínimas previstas para atender à demanda são inferiores às áreas existentes. fácil de se compreender o fato, se nos lembrarmos de que o prédio onde funciona o SPA-Agua Rasa está sendo utilizado tal como fol locado, sem sofrer qualquer adaptaçāo. Tratase, pois, de instalação improvisada, sem qualquer adequação à função que exerce.

Quanto ao PA-Cidade Dutra, trata-se de prédio de excelente estrutura, localizado à entrada de um conjunto residencial concebido, há mais do 30 anos, por notável urbanista, para ser uma cidade satélite, em relação ao núcleo urbano de São Paulo. Existem alí condições excelentes para a instalação de um PA de elevada dinâmica funcional; no momen. to, contudo, por razōes administrativas, sua capacidade de atendimento 6 pequena, o que se traduz na área reduzida prevista para atender os que o procuram. $O$ que se pretende é no futuro, tão logo seja possível, melhorar as condições de funcionamento nesse PA, elevando sua capacidade de atendimento; poderemos, então, chegar a 150 ou 200 atendimentos por dia e ocupar toda a área útil do predio $\left(1000 \mathrm{~m}^{2}\right)$, em lugar dos $500 \mathrm{~m}^{2}$ que são previstos como necessários no momento atual. 
LIMA-GONCALVES, E. et. al. - Plano de reformulaçăo da assistencia ambulatorial do Instituto Nacional de Previdência Social na cidade de Săo Paulo. Rev. Saúde publ., S. Paulo, 6: 135-46, 1972.

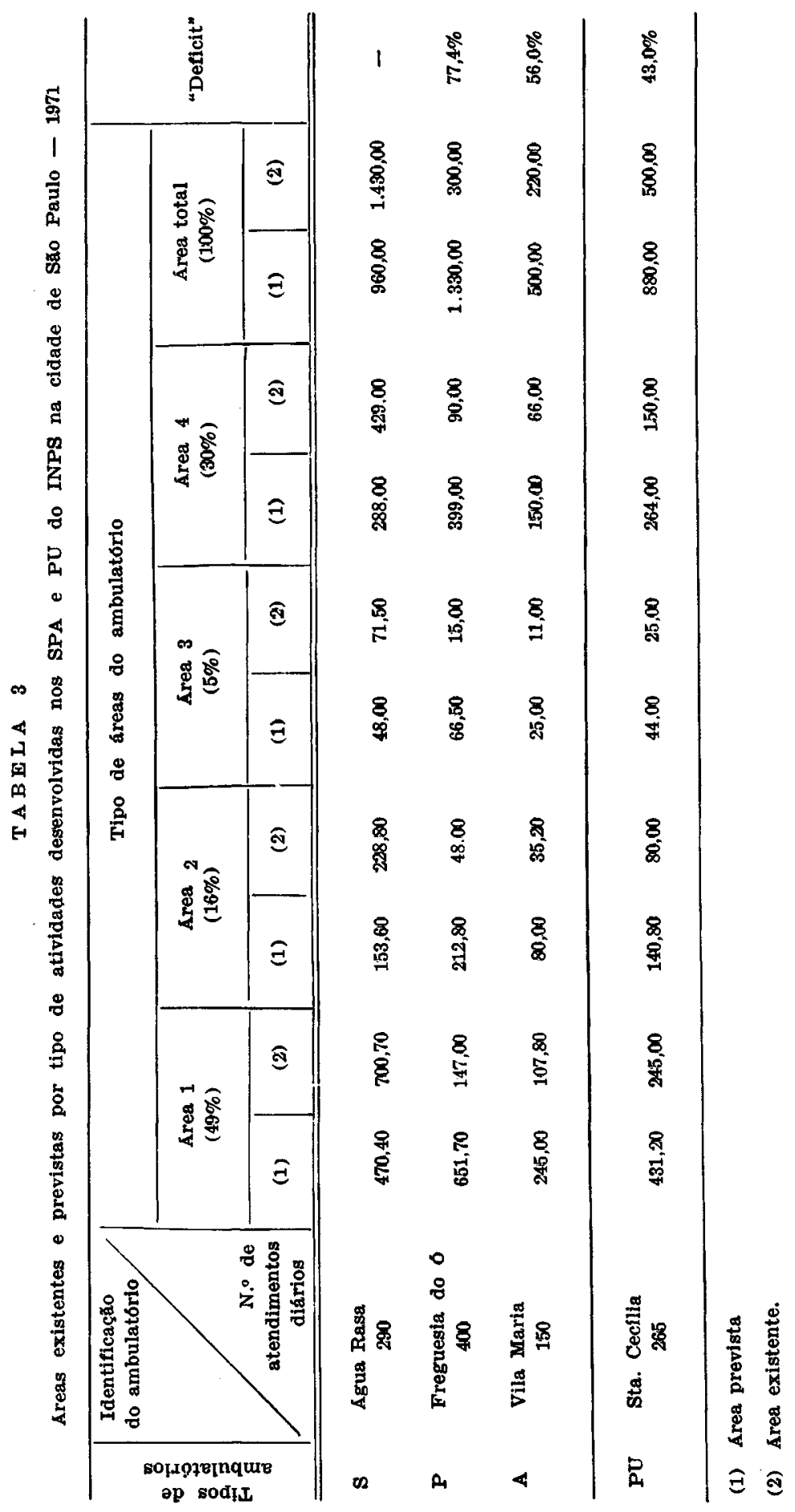




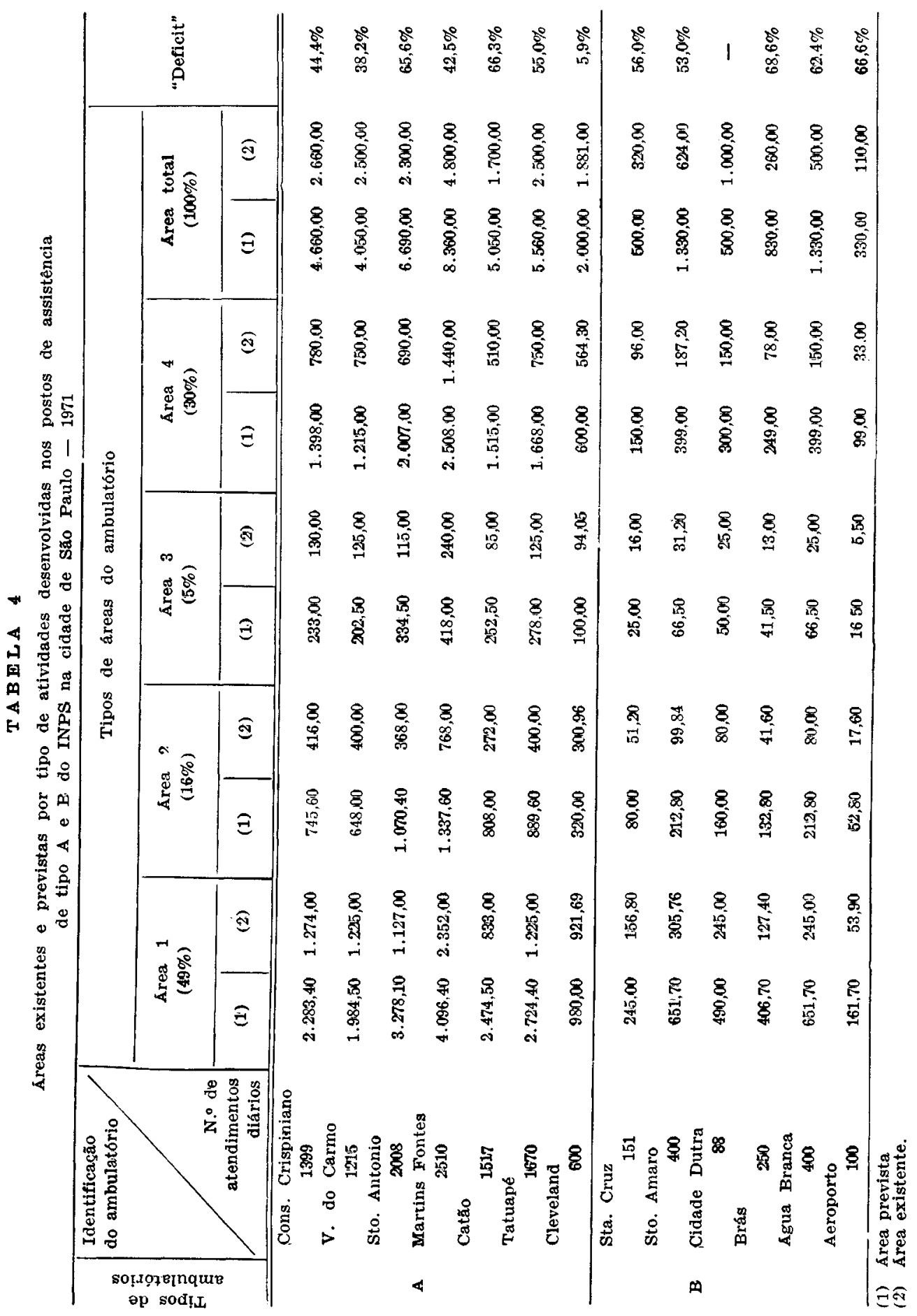


LIMA-GONÇALVES, E. et. al. - Plano de reformulaçăo da assistência ambulatorial do Instituto Naclonal de Previdencia Social na cidade de Săo Paulo. Rev. Saúde públ., S. Paulo, 6: 135-46, 1972.

Em todos os demais Postos de Assistência, as áreas necessárias para atender à demanda atual são sempre inferiores às existentes. Com o objetivo de quantificar melhor essa insuficiência, nas Tabelas 3 e 4 figura uma última coluna onde aparecem porcentagens que representam a relação entre a área existente a prevista. Pode-se, então, verificar que aquela é inferior a essa em porcentagens que variam entre $5,9 \%$ e $77,4 \%$; na grande maioria dos casos a carência de áreas e de ordem de 50 a $60 \%$, demonstrando que a planta física atual dos Postos de Assistência aproxima-se, em geral, da metade das dimensões que deveriam ter.

A terceira série de deficiências observada prende-se à localização dos ambulatórios do INPS na cidade de São Paulo. Com a unificação dos antigos Institutos de Aposentadorias e Pensões, bem como dos Serviços de Assistência Médica Domiciliar e de Urgência, o INPS recebeu o acervo dos respectivos serviços médicos; acontece que a preocupação anterior à unificação era a instalação de ambulatórios de cada Instituto na zona central da cidade, deixando para segundo plano a área periférica e até mesmo a zona intermediária da cidade. O resultado é que grandes faixas da população obrigam-se hoje a longos deslocamentos para se valerem dos serviços médicos próprios do INPS, mercê da localização absolutamente inadequada dos diversos ambulatórios.

A triplice série de deficiências apontadas - de pessoal, de área e de localização - faz com que a assistência ambulatorial que se consegue oferecer aos segurados da Previdência Social, padeça de sérias deficiências. Para corrigí-las não têm bastado a boa vontade e dedicação dos funcionários de todas as categorias, ligados de alguma forma a assistência médica do INPS em São Paulo; a consequiência é a formação de filas diárias nos ambulatórios e.o atraso na marcação de consultas, o qual chega a ser considerável em certas especialidades.

BASES DO PLANO DE REFORMULAÇBO DA ASSISTENCIA AMBULATORIAL DO INPS NA CIDADE DE SAO PAULO

Diante do que se expôs, partiu a Coordenação de Assistência Médica do INPS em São Paulo para a elaboração de um plano de ampliação e reformulação da assistência médica ambulatorial do Instituto, em São Paulo. As bases desse plano, já apresentado à Direção Superior do INPS e dela merecendo integral aprovação, foram: 1 - dimensionamento das unidades a serem construídas e definição daquelas que devem ser mantidas, de acordo com as necessidades das diferentes zonas da cidade ; 2 - localização adequada das novas unidades; 3 - implantação de sistema de unidades periféricas; 4 - definição de retaguarda hospitalar adequada.

A primeira preocupação na elaboração do plano foi definir as necessidades da população previdenciária de São Paulo, relativa a novos ambulatórios. No estudo elaborado para o GEGRAN 5, relativo às necessidades da população da Grande São Paulo, apresenta-se na área de saúde a sugestão de que a unidade ambulatorial deve prever o deslocamento máximo de $1.000 \mathrm{~m}$ pelo usuário. No campo da assistência médica previdenciária, não há, contudo, possibilidade de se obedecer a essa sugestão; daí a definição de 5 novas unidades ambulatoriais integradas, destinadas, ou a substituir ambulatórios já amplamente superados pela precariedade de suas instalações, ou a atender a regiōes até agora desassistidas. Ao lado dessas novas unidades, definiu-se a ma. nutenção de dois grandes ambulatórios atuais, bem como a ativação das medidas destinadas à construção de mais um 
LIMA-GONCALVES, E. et. al. - Plano de reformulaça da assistência ambulatorial do Instituto Nacional de Previdência Social na cidade de Săo Paulo. Rev. Saíde publ., S. Paulo, 6: 135-46, 1972.

grande Posto de Atendimento, já com todas as providéncias administrativas indispensáveis, inteiramente atendidas

A segunda linha de unidades ambulatoriais seria representada por ambulató rios de tipo $B$ e postos de SPA, sendo 3 já existentes e 2 a serem instalados no prédio de duas das novas agências metropolitanas do INPS, cuja construção já foi aprovada.

Perifericamente, o plano prevê a implantação de unidades ambulatoriais em conjunto com a Secretaria de Saúde do
Estado de São Paulo; esta iniciativa é fruto de convênio celebrado entre o INPS e o governo do Estado. A previsão é de 18 postos de atendimento, 9 dos quais já estão em fase de implantação.

Todas essas unidades ambulatoriais terão por retaguarda um hospital de base, de maneira a integrarem-se em conjuntos harmônicos de recursos integrados $e$ distribuídos de maneira racional.

Teríamos assim, definidas 5 regiōes de atendimento médico na cidade de São Paulo, analisadas na Tabela 5 .

TABELA 5

Integração dos ambulatórios previstos pelo INPS com recursos médico-hospitalares da cidade de São Paulo

\begin{tabular}{l|c|c|c|c}
\hline $\begin{array}{c}\text { Regióes } \\
\text { da } \\
\text { cidade }\end{array}$ & $\begin{array}{c}\text { Hospital } \\
\text { de } \\
\text { base }\end{array}$ & $\begin{array}{c}\text { Ambulatórios } \\
\text { integrados } \\
\text { (Tipo A) }\end{array}$ & $\begin{array}{c}\text { Ambulatórios } \\
\text { secundários } \\
\text { (Tipo B) }\end{array}$ & (Centros de Saúde) \\
\hline Centro & $\begin{array}{l}\text { Hospital Cen- } \\
\text { tral da Santa } \\
\text { Casa de Săo } \\
\text { Paulo }\end{array}$ & $\begin{array}{c}\text { PA Martins } \\
\text { Fontes } \\
\text { PA Várzea do } \\
\text { Carmo }\end{array}$ & PA Cleveland & \\
\hline
\end{tabular}

\begin{tabular}{|c|c|c|c|c|}
\hline Sul & $\begin{array}{l}\text { Hospital Bri- } \\
\text { gadeiro do } \\
\text { INPS }\end{array}$ & $\begin{array}{l}\text { PA Santo } \\
\text { Antonio } \\
\text { PA Pinheiros }\end{array}$ & & $\begin{array}{l}\text { Săo Joăo Clímaco } \\
\text { Vila Alpina } \\
\text { American6polis } \\
\text { Campo Limpo } \\
\text { Vila Madalena } \\
\text { Caxingui } \\
\text { Capela do Socorro }\end{array}$ \\
\hline Oeste & $\begin{array}{l}\text { Hospital } \\
\text { Sorocabana }\end{array}$ & PA Lapa & $\begin{array}{l}\text { SPA Fregue- } \\
\text { sia do } 0\end{array}$ & $\begin{array}{l}\text { Vila Brasilandia } \\
\text { Vila das Belezas } \\
\text { Vila Mangalot } \\
\text { Vila Nova Cachoeirinha }\end{array}$ \\
\hline Leste & $\begin{array}{l}\text { Hospital } \\
\text { Hell6polis do } \\
\text { INPS }\end{array}$ & $\begin{array}{l}\text { PA Heliópolis } \\
\text { PA Sta. Cruz }\end{array}$ & $\begin{array}{l}\text { SPA Vila } \\
\text { Mariana } \\
\text { SPA Agua } \\
\text { Rasa }\end{array}$ & $\begin{array}{l}\text { Vila Cangaiba } \\
\text { Ermelindo Matarazzo } \\
\text { Vila Guilhermina } \\
\text { Vila Olinda }\end{array}$ \\
\hline Nordeste & $\begin{array}{l}\text { Hospital Såo } \\
\text { Luiz Gonzaga } \\
\text { da Santa Casa }\end{array}$ & $\begin{array}{l}\text { PA Tatuape } \\
\text { PA Santana }\end{array}$ & $\begin{array}{l}\text { SPA Brás } \\
\text { SPA V. Maria }\end{array}$ & $\begin{array}{l}\text { Vila Aurora } \\
\text { Vila Bonilha } \\
\text { Vila Medeiros }\end{array}$ \\
\hline
\end{tabular}


LIMA-GONCALVES, E. et. al. - Plano de reformulação da assistência ambulatorial do Instituto Nacional de Previdência Social na cidade de Săo Paulo. Rev. Saúde prubl., S. Paulo, 6: 135-46, 1972.

Das unidades ambulatoriais indicadas, algumas correspondem às existentes e que devem ser mantidas, ao passo que outras devem ser construídas. No primeiro Grupo contam-se: PA-Martins Fontes, PA-Sto. Antonio, PA-Sta. Cruz, PACleveland, PA-Sto. Amaro, PA-Cidade Dutra, SPA-Freguesia do $O$, SPA-Agua Rasa, SPA-Vila Maria. No segundo incluem-se: PA-Várzea do Carmo, PA-Pinheiros, PALapa, PA-Heliópolis, PA-Tatuapé, PA-Santana, SPA-Brás e SPA-Vila Mariana. Es. clareça-se que as unidades indicadas como PA-Várzea do Carmo, PA-Tatuapé e SPA-Brás cotrespondem a novos ambulatórios a serem construídos em substituição a unidades de mesma localização, as quais serão fechadas. A comparação entre as Tabelas 1, 2 e 5 mostra que, além das 3 unidades ambulatoriais referidas atrás, outras serão também fechadas por sua onerosa e reduzida capacidade operacional. Trata-se do PA-Conselheiro Crispiniano, PA-9 de Julho e PA-Aeroporto. O PA-Brigadeiro será transformado, como diremos adiante, em ambulatório anexo ao Hospital Brigadeiro; o PA-Catão será substituído pelo PA-Lapa e PAAgua Branca será fechado para dar lugar a um serviço especializado de recursos complementares de diagnóstico.

Além da rede de ambulatórios descrita, a qual deverá dispor-se em 3 círculos concêntricos na cidade, contando porém, com um critério de distribuição regional ligada a 5 hospitais de base, haverá ainda algumas iniciativas de ordem complementar.

Inicialmente, cada um dos Hospitais próprios do INPS - Hospital Brigadeiro, Hospital Heliopolis e Hospital Ipiranga - irá contar com um ambulatório anexo, que embora não à disposição do público em geral, permitirá utilização mais dinâmica dos leitos hospitalares próprios o que resultará indiretamente em melhor assistência médica aos segurados da Previdência Social.

Em segundo lugar, no que se refere aos atendimentos de urgência está definido que a existência dos postos de urgência só tem sentido quando está anexa ao hospital ou quando contam esses postos com retaguarda hospitalar imediata. Assim, em cada um dos hospitais próprios acima mencionados já funciona um serviço de emergência. Na mesma perspectiva, o Posto de Urgência que funcionava à Rua Vergueiro e que tinha uma demanda de cerca de 600 atendimentos diários, foi fechado, sendo seus serviços transferidos para o Hospital Matarazzo, onde os setores de adultos e de crianças passaram a funcionar separadamente, em instalações muito melhores. A mesma orientação deverá ser aplicada em referência ao último PU que ainda funciona desvinculado de hospital e que é o PU-Sta. Cecília.

Em terceiro lugar, existe setor de importância no rendimento da rede de assistência ambulatorial, o qual é representado pelos serviços complementares de diagnóstico. $\mathrm{O}$ plano ora analisado inclui a centralização de alguns desses serviços, como os de radiologia clínica e os de laboratório clínico mais refinados, endoscopia peroral e peranal, bem como de técnicas radioisotópicas. $O$ serviço será instalado no prédio onde atualmente funciona o PA-Agua Branca, que será extinto, como já foi dito.

Por último, grande preocupação dos responsáveis pela assistência médica do INPS em São Paulo é a assistência psiquiátrica. Daí a implantação de um ambulatório especializado, a ser localizado em prédio de propriedade do Instituto, situado à Rua Prates; neste deverão funcionar consultórios especializados, 0 arquivo e secretaria centrais de âmbito estadual, bem como seção de internaçōes de urgência, para triagem após permanência de 24 a 48 horas. Em estreita vinculação com este ambulatório psiquiátri- 
LiMA-GONCGALVES, E. et. al. - Plano de reformulaçăo da assistência ambulatorial do Instituto Na. cional de Previdência Social na cidade de Săo Paulo. Rev. Saúde públ., S. Paulo, 6: 135-46, 1972.

co funcionará o Hospital Psiquiátrico Santo Antonio, a ser instalado em prédio já iniciado no Alto do Mandaqui; tratase do primeiro hospital psiquiátrico do INPS no Brasil, destinado, por conseguinte, a desempenhar importante papel na apreciação do tratamento psiquiátrico hospitalar, tanto no que se refere a custos, como a técnicas terapêuticas. $O$ que se pretende com a instalação deste Hospital não é evidentemente resolver os problemas de leitos hospitalares de psiquiatria, mas permitir definição de esquemas mais eficientes de controle a serem aplicados na rede de hospitais particulares que prestam essa assistência aos previdenciários em todo o Estado.

Com o plano de assistência ambulatorial descrito, poderemos dispor de recursos para obedecer as seguintes estimativas de atendimento anual.

T A B ELA 6

Capacidade de atendimento da rede ambulatorial proposta pelo INPS na cidade de São Paulo - 1972

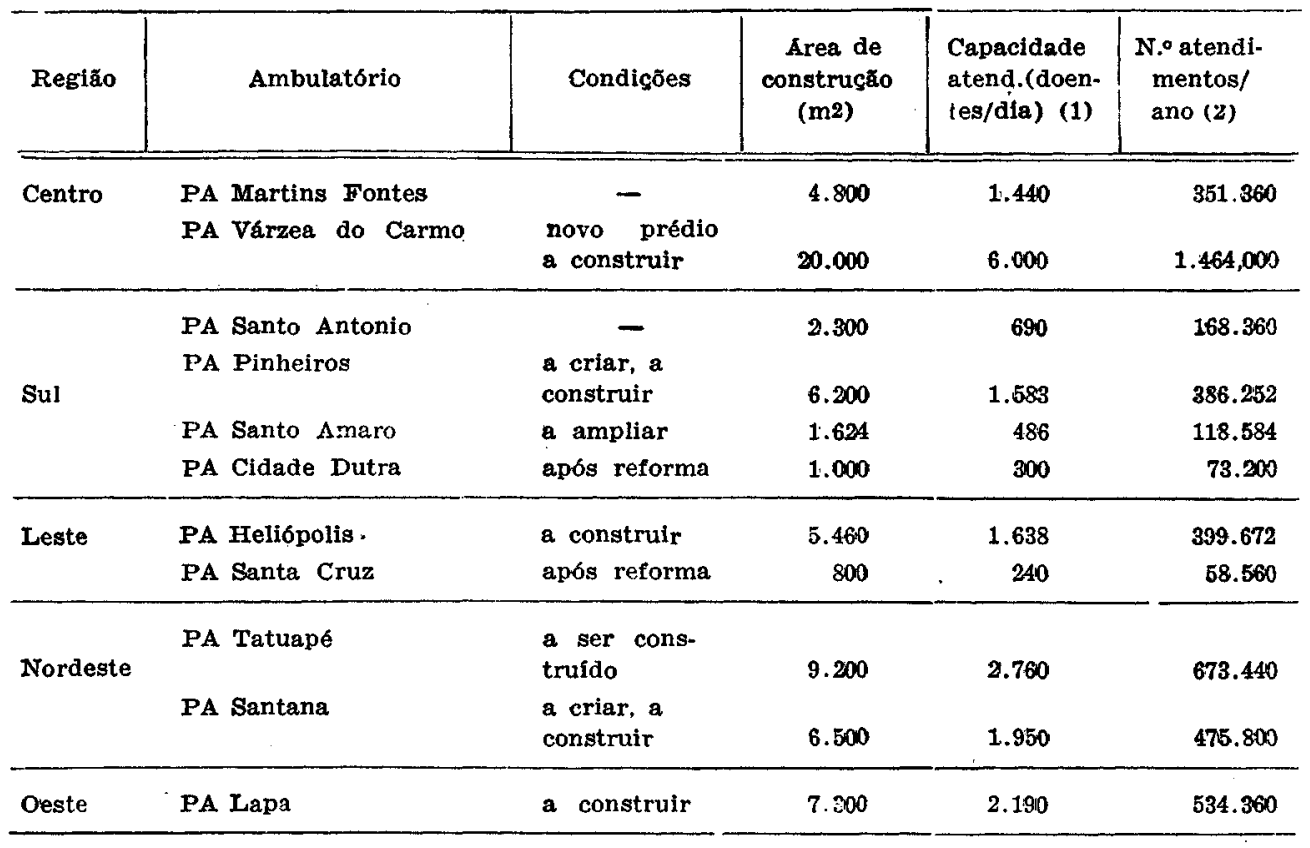

(1) Os números referidos foram corrigidos para real capacidade dos PAs existentes, cuja área nåo pođe ser ampliađa.

(2) Os totais foram obtidos multiplicando a capacidade de atendimentos por dia pelo número aproximado de dias úteis por ano (244).

\section{COMENTARIOS E CONCLUSÓES}

Se considerarmos que a população previdenciária a ser atendida pela rede ambulatorial do município de São Paulo é estimada em cerca de 4.580 .535 beneficiários, verificamos que a estimativa de atendimento por ano encontrada (Tabela 6), igual a 4.703 .538 , supera em muito $\circ$ indice de uma consulta por ano para cada beneficiário, já que não foram computadas as estimativas de atendimento nos ambulatórios de categoria $B$ (Servi- 
LIMA-GONGALVES, E. et. al. - Plano de reformulaça da assistência ambulatorial do Instituto Nacional de Previdência Social na cidade de São Paulo. Rev. Saúde píbl., S. Paulo, 6: 135-46, 1972.

co de Pronto Atendimento), e nos Centros de Saúde da Secretaria da Saúde do Estado de São Paulo.

Esse aparente "superavit" em relação aos atuais índices de atendimento, deverá ser analisado levando em conta o crescimento vegetativo e social da população, uma vez que o plano acima exposto, já em desenvolvimento, obedecerá ao seguinte programa de execução:

curto prazo: reformas, ampliaçōes e adaptações em unidades já existentes;

médio prazo: construção de novas unidades em terrenos próprios;

longo prazo: construção de novas unidades em terrenos que deverão ser adquiridos.

Dessa maneira, no momento em que as unidades assistenciais estiverem todas em operação, a população a ser assistida será seguramente maior do que atualmente. Além disso, fator de fundamental importância na definição do número de consultas médicas que cada membro da comunidade solicita por ano, é o padrão de assistência médica oferecido. Daí nossa avaliação colocada acima, de uma consulta por ano para cada beneficiário do INPS, tomando-se por base pesquisa realizada durante o ano de 1969, em que esse índice foi de 0,96 consultas por ano. Durante $o$ ano de 1971 , foi realizada pesquisa semelhante na cidade de Campinas, onde a assistência ambulatorial é superior à oferecida em São Paulo. O resultado confirma o que dissemos, uma vez que $o$ indice obtido foi de $1,48 \mathrm{con}$ sultas por ano. Como o objetivo do presente plano é exatamente oferecer ao previdenciário assistência de melhor pa- drão do que a atual, é de esperar incremento do índice básico de uma consulta por ano por segurado da Previdência Social.

\section{RSPSP-125}

Lima-Gonçalves, E. et al. - [Reformulation plan of the outpatient clinics of National Institute of Social Welfare in the city of S. Paulo, Brazil]. Rev. Saúde públ., S. Paulo, 6:135-46, 1972.

SUMmary: A reformulation plan of the outpatient clinics provided by the National Institute of Social Welfare to its associates and their dependents in the city of $S$. Paulo, was presented. The importance of such study is stressed by the small amount of available hospital beds. In the first part of the plan an appraisal of the existing situation have been made, considering three aspects of the problem: amount of personnel, size of the available units and their location related to the urban area. The result of their study showed defficiency in all existing outpatient clinics, as far as the three aspects are concerned. Based on this data a plan for the reformulation of the outpatient clinic division was made, considering an average of 4,500,000 as the total amount of persons using the Institute facilities in the city of S. Paulo. This plan is based in four fundamental points: 1. Provision of adequate physical space for the new units to be built, and determination of those to be maintained, considering the local necessities within the city. 2. Adequate location of the new units. 3. Implantation of new peripheral units, as a result of the integration of units of the State Public Health Department. 4. Definition of a proper hospital facilities backing. The total number of patient to be treated by the so stablished outpatient clinic division will be around 5,000,000 by year.

UNITERMS: Outpatient clinics*; Social welfare*; São Paulo, Brazil*; Community assistance. 
IIMA-GONÇALVES, E. et. al. - Plano de reformulação da assistencia ambulatorial do Instituto Nacional de Previdência Social na cidade de São Paulo. Rev. Saúde públ., S. Paulo, 6: 135-46, 1972.

\section{REFERENCIAS BIBLIOGRAFICAS}

1. ALENCASTRE, G. M. - Deficiencia en camas de una comunidad. Papel del ambulatório. Rev. paul. Hosp., 11 (10): 26-31, 1964.

2. LIMA - GONÇALVES, E.; DIAS, M. M. \& MATTOS, H. M. B. - A assistencia hospitalar no ambito da previdencia social no Estado de são Paulo. Rev. Saúde publ., S. Paulo, 6: 35-43, 1972.

3. LIMA - GONÇALVES, E.; FUCHS, M. \& OGUISSO, T. - Programa de dimensionamento de um ambulatório. Rev. paul. Hosp. [no prelo].
4. ORganizaço MUNDIAI DA SAUDE. Comité de Expertos en Organización de la Asistencia Médica. - Función de los hospitales en los programas de protección de la salud: primer infor. me. Ginebra, 1957. (Ser. inf. tecn., 122).

5. SÁ PaULo. Secretaria de Economia e Planejamento. Grupo Executivo da Grande Săo Paulo (GEGRAN) - Plano metropolitano de desenvolvimento integrado na Grande São Paulo. São Paulo, 1971.

Recebido para publicação em 11-2-1972

Aprovado para publicagão em 25-4.1972 